Volume 8, Issue 1, 21 - 30.

ISSN: 2165-8714

http://www.eu-jer.com/

\title{
Test Anxiety: Gender Differences in Elementary School Students
}

\author{
Utkun Aydin * \\ American University of the Middle East, KUWAIT
}

Received: August 27, 2018 - Revised: October 6,2018 - Accepted: November 2, 2018

\begin{abstract}
Students' test anxiety is known to have significant influences on essential academic outcomes, and given the increased testing of school-aged children gender differences also appear in dimensions of test anxiety: thoughts, off-task behaviors, and autonomic reactions. This study examined: (i) whether there was a pattern of correlations existing among three dimensions of test anxiety that were tapped by the Children's Test Anxiety Scale (Wren and Benson, 2004) and (ii) whether gender differences existed in the strength of these test anxiety dimensions. Students $(\mathrm{N}=414)$ from 3 public schools, attending to the fourth grade $(205$ Females; 209 Males) were asked to rate on the thoughts (cognitive), off-task behaviors (behavioral), autonomic reactions (physiological) dimensions. The results revealed a strong relationship between thoughts and autonomic reactions $(\mathrm{r}=.57)$. Applying a multivariate approach, gender differences were found to be significant in overall test anxiety favoring females. Results also revealed a small female advantage for thoughts and autonomic reactions, $\eta^{2}=.012$ and $\eta^{2}=.016$; but quite a small male advantage for off-task behaviors $\eta^{2}=.009$. Taken as a whole, we need to seriously consider the implications of these differences and pay attention particularly to females in elementary schools.
\end{abstract}

Keywords: Test anxiety, test attitude, gender differences, elementary education, children's test anxiety scale.

To cite this article: Aydin, U. (2019). Test anxiety: Gender differences in elementary school students. European Journal of Educational Research, 8(1), 21-30. doi: 10.12973/eu-jer.8.1.21

\section{Introduction}

Over the past 100 years both psychologists and parents have been fascinated with the idea of test anxiety in schoolaged children (Liebert and Morris, 1967; Putwain, 2007; Putwain, Daly, Chamberlein, and Sadreddini, 2016; Ringeisen, Raufelder, Schnell, and Rohrmann, 2016; Sarason, 1980; Schwarzer and Jerusalem, 1992; Spielberger, Gonzalez, Taylor, Algaze, and Anton, 1978; Zeidner, 1998). Not surprisingly, test anxiety appears in children whose parents have overly high expectations for their children's behaviors (e.g., parents who react critically to their children's performance in school settings) (Sarason, Davidson, Lighthall, Waite, and Ruebush, 1960).

Building on this view, the influences and consequences of test anxiety remain a hotly debated issue in education as the level of testing in schools continues to increase. There is a growing evidence that test anxiety is an important psychological construct that has significant influence on essential academic outcomes and subsequent achievement (Hembree, 1988). At the same time, it may overburden students by causing unpleasant emotions (e.g., worry) in students and their parents and thus have negative implications for both school and family life (Mulvenon, Stegman, and Ritter, 2005). As all the students performed poorly when exposed to highly evaluative classrooms and in addition to that, particularly the test-anxious students, were less motivated in such settings (Hancock, 2001), test anxiety can also be expected to have implications for students' academic achievement and motivation. Yet despite a growing volume of research showing that test anxiety is one of the crucial learner characteristics that is applicable to educational practice (Pintrich and Schunk, 1996) and despite the obvious relevance of test anxiety to educational problems, there have been few attempts to systematically analyze the individual differences in test anxiety. This study strived to fill this gap in test anxiety research by taking into account the disparity across genders.

Researchers have shown that levels of test anxiety and concomitant patterns of performance are different apparently for females and males (e.g., Everson, Millsap, and Rodriguez, 1991; Hembree, 1988; Wigfield and Eccles, 1989). The present study investigated this important issue of potential differences between female and male students in elementary school using a sample of fourth graders. The findings may lead to a better understanding of gender issues related to this psychological construct that was considered to be a cornerstone standing as an important educational problem (Everson et al., 1991) affecting students in schools as well as universities.

\footnotetext{
* Correspondence:

Utkun Aydin, College of Engineering and Technology, American University of the Middle East, Kuwait.

$\bowtie$ Utkun.Aydin@aum.edu.kw
} 
Test Anxiety

Test anxiety was defined as "a set of cognitive, physiological, and behavioral responses related to concerns about possible failure or a poor performance on a test or a similar evaluative situation" (Bodas, Ollendick, and Sovani, 2008, p. 387). In relation to anxiety in general, test anxiety is the anxiety that occurs in evaluative situations (Zeidner and Mathews, 2005), and that reflects the fear of failure and/or worry over performance (Hong, 1999; Meijer, 2001). From this perspective, it can be concluded that test anxiety (i) occurs in a context, where individuals are evaluated in terms of an assessment performance, and by its very nature, (ii) embodies a social dimension about how this performance will be judged by others or evaluated by, for instance, the teacher (Putwain, 2008). In practical terms, low-anxious individuals fully concentrate on the task at hand while they are being evaluated, whereas high-anxious individuals tend to divide their attention among the task and their cognitions and emotions about how they are doing, and thus maintaining less focus on task implementation and so exhibit poorer performance.

Besides, the manifestations of test anxiety include cognitive (e.g., self-deprecating ruminations), behavioral (e.g., study skills), and physiological (e.g., autonomic arousal) dimensions (Putwain, 2008). Although test-anxious children and adults may experience similar cognitions and exhibit alike behaviors during test taking (Zatz and Chassin, 1985), several recent educational trends are likely to increase test anxiety among school-aged children (Hill and Wigfield, 1984). Indeed, studies employing undergraduate/graduate student populations generally emphasized a declining trend towards the later school years (e.g., Hembree, 1988). Drawing upon a comprehensive review of the literature in test anxiety, Wren and Benson (2004) proposed that children's test anxiety is comprised of three distinct yet interrelated dimensions: (i) Thoughts, (ii) Off-task behaviors, and (iii) Autonomic reactions.

The thoughts dimension reflects cognitive test anxiety, occurs before, during, or after testing, and involves individuals' internal dialogue regarding evaluative situations. It centers on self-critical (e.g., comparing self-performance to peers), test-relevant (e.g., feeling unprepared for evaluative situations), and test-irrelevant (e.g., causing sorrow for parents) concerns. The off-task behaviors dimension mirrors behavioral test anxiety, occurs during testing, and includes attentional symptoms of task-irrelevant stimuli. It focuses on nervous habits such as auto-manipulation (e.g., playing with hair) or object manipulation (e.g., biting pencils), and other distracting, inattentive behaviors such as looking around the classroom. The autonomic reactions dimension displays physiological test anxiety, appears before or during testing, and encompasses somatic responses to test-related stress. It embodies physiological manifestations (e.g., perspiring) and somatic signs (e.g., increased galvanic skin response and dizziness).

Several studies in children's test anxiety typically focused on the impact of test anxiety on academic achievement (e.g., Pintrich and Schrauben, 1992), development of test anxiety prevention and intervention programs in schools (e.g., von der Embse, Barterian, and Segool, 2013), and evaluation of the psychometric properties of test anxiety inventories (e.g., Lowe and Lee, 2008). Researchers have also taken into consideration the underlying locus of the impact of the children's test anxiety about specific school subjects such as mathematics (Ma, 1999; Zaslavsky, 1994), science (Udo, Ramsey, and Mallow, 2004), and foreign languages (Abu-Rabia 2004; Yan and Horwitz, 2008). Among these lines of research there is substantial evidence that there are differences in test anxiety across gender among students in different school settings (e.g., Lowe and Lee, 2008). Although gender differences in test anxiety and its dimensions were well-documented (for a review, see Zeidner, 1998), there is still a need to understand these differences more in detail to cope with test anxiety in school-aged children (e.g., Hembree, 1988; Stober and Pekrun, 2004). Therefore, a critical investigation of the gender disparity in children's overall test anxiety in general and its dimensions (i.e., thoughts, offtask behaviors, and autonomic reactions) in particular is paramount.

\section{Gender Differences}

Numerous studies using samples from different countries provide evidence that females tend to report higher levels of overall test anxiety than do males (Lowe and Lee 2008; Putwain, 2007; Segool, Carlson, Goforth, von der Embse, and Barterian, 2010). This effect is frequently attributed to socialization practices that encourage females to display their emotions/feelings more openly whereas pushing males to exhibit defensiveness about admitting their emotions/feelings (Bodas et al., 2008); and also to parental expectations that force females to achieve better and thus trigger females' sensitivity about getting social approval from adults than do males (Wigfield and Eccles, 1989).

When domain-specific test anxiety is taken into account, females again report higher anxiety levels in worry and emotionality (Cassady and Johnson, 2002; Putwain, 2008). This result is not surprising when gender stereotyping in education is taken into consideration (Andre, Whigham, Hendrickson, and Chambers, 1999). That is, for instance, different school subjects (e.g., mathematics and science) may elicit worry and/or emotionality in females and males (Jacklin, 1989).

In a related vein, there is an evidence that females reported greater levels of thoughts and autonomic reactions than males did, whereas no significant differences were found in off-task behaviors across gender (Wren and Benson, 2004). While some studies documented no significant differences in thoughts and off-task behaviors across gender, they showed that females reported higher levels of autonomic reactions than males did (Nyroos et al., 2015). Interestingly, some researchers reported no significant gender differences in thoughts, off-task behaviors, and autonomic reactions dimensions of test anxiety (Putwain and Daniels, 2010). Given the worldwide impact of high-stakes examination 
systems in which poor performance on a test is associated with significant and lifelong negative consequences (Bodas and Ollendick, 2005) it is possible that this excessive pressure may cause both females and males to experience similar levels of test anxiety. This might also be due to males' greater defensiveness about admitting their anxiety that put forth the experience of test anxiety being similar for females and males (Wigfield and Eccles, 1989).

In this accordance, there have been few national studies attempting to systematically investigate students' anxiety towards test-taking, specifically the gender differences in Turkish students' test anxiety. Four notable exceptions include Bacanli and Surucu (2006); Oksal, Durmaz, and Akin (2013); and Yenilmez and Ozbey (2006), and the results are mixed. The majority of national research attempted to ascertain the influence of gender on test anxiety with reference to anxiety towards a particular subject such as mathematics (Oksan et al., 2013; Yenilmez and Ozbey, 2006). Findings revealed either a typically stronger test anxiety in females (e.g., Oksan et al., 2013) or no significant gender differences (e.g., Yenilmez and Ozbey, 2006). In the study reported by Bacanli and Surucu (2006), gender differences in the overall test anxiety were examined. The results showed that test anxiety was differentially related to gender with females reporting higher than males at the total test anxiety level.

Viewed together, findings of both international and national research show that some kind of gender difference is present and exploring this disparity in test anxiety with regard to different dimensions - thoughts, off-task behaviors, and autonomic reactions - is important (Wren and Benson, 2004) because of having educational implications for the appraisal of assessments as well as making several contributions for the learning and achievement of students (Putwain and Daniels, 2010).

\section{Method}

\section{Research Goal}

The aims of the present study were twofold. First, it was examined whether there were interrelations among the overall test anxiety and its three components. From the literature discussed above, it was hypothesized that there would be significant relationships among fourth grade students' overall test anxiety and its three components, in general. Additionally, on the basis of the previous research (e.g., Wren and Benson, 1994) that focused on the development and validation of test anxiety measures (e.g., CTAS) it was hypothesized that there would be significant relationships among fourth grade students' thoughts, off-task behaviors, and autonomic reactions, in particular. Second, it was examined whether there were gender differences in fourth grade students' thoughts, off-task behaviors, and autonomic reactions. An extended corollary purpose of this aim was to provide a particular lens into the gender differences in overall test anxiety. On the basis of the literature, it was hypothesized that females tend to report higher levels of test anxiety at thoughts, off-task behaviors, and autonomic reactions and that gender differences are present in overall test anxiety. Accordingly, research questions of the present study were the following: (1) Are there significant relationships among fourth grade students' overall test anxiety and thoughts, off-task behaviors, and autonomic reactions?; (2) Are there significant gender differences in fourth grade students' overall test anxiety?; and (3) Are there significant relationships among fourth grade students' thoughts, off-task behaviors, and autonomic reactions?

\section{Sample and Data Collection}

Participants were selected from three public schools, which were similar in size, socioeconomic status (SES) and academic achievement. The three schools were in Istanbul, a major metropolitan city in Turkey. These schools represented a diverse socio-demographic body of students (i.e., low to medium SES) and were located in, to some extent, deprived districts of Istanbul, as a proxy indicator of low income and thus SES. With 15 participating classes, the initial sample included 439 students (215 females, $48.97 \%$ and 224 males, $51.02 \%$ ) who were present on the days of data collection. Turkish was the first language of the participants. In accordance with Scott and Haydon (2005), who provided guidelines for working with children as research participants, institutional (e.g., Ethics Committee approval), parental (e.g., The Child Parental Permission Letter) and pupil (e.g., The Student Assent Form) consents were provided.

Preliminary analysis of the completed questionnaires revealed that the average percentage of missing data was $0.35 \%$ and $0.16 \%$ for the demographic variables and questionnaire items, respectively. For the complete data set the average percentage of missing data was $0.09 \%$. Following that, the item non-response in the data set was examined by conducting Little's MCAR test (Little, 1988). Results indicated that the data were missing completely at random (MCAR) $(p=.456, p>.05)$. Regarding that, the listwise deletion procedure that would give unbiased estimates (Cohen, Cohen, West, and Aiken, 2003) was used. 25 cases were excluded based on the following standpoints: (a) they showed insincerity in their responses (13 cases; e.g., all "1"s or all "5"s), (b) they did not complete the survey (5 cases; e.g., drawings on the survey), (c) they represent multivariate outliers (5 cases) detected via using Mahalanobis distances (number of dependent variables = 3; critical value $=16.27$ ), and (d) they did not report demographic information $(2$ cases; e.g., gender not specified). Upon completion of this process the final sample was comprised of 414 students (205 females, $49.5 \%$ and 209 males, $50.5 \%)$ with a mean age of $9.60(S D=1.35)$.

\section{Measures}

Children's Test Anxiety Scale (CTAS). To measure students' thoughts, off-task behaviors, and autonomic reactions applied during test taking process, the CTAS, originally developed by Wren and Benson (2004) was used. The instrument 
consisted of 30 items. Example of the items from the thoughts (13 items), off-task behaviors (8 items), and autonomic reactions (9 items) were "While I am taking tests, I wonder if I will pass.", "While I am taking tests, I play with my pencil.", and "While I am taking tests, I feel scared.", respectively. Participants rated themselves on the 4-point scale $(1=$ almost never, $2=$ some of the time, $3=$ most of the time, and $4=$ almost always). The possible scores on the CTAS ranged from 30 (low test anxiety) to 120 (high test anxiety).

The permission for the adaptation of the CTAS into Turkish was taken from Dr. Wren in October 14, 2014 via email. Accordingly, the cross-cultural validation of the CTAS was conducted by Aydin and Bulgan (2017) within two studies regarding the recommendations of the Standards for Educational and Psychological Testing (AERA, APA, and NCME, 1999). Study 1 involved Phase 1: translation of the CTAS and Phase 2: piloting of the instrument. In order to test the applicability of the CTAS, Study 2 involved Phase 1: test administration, Phase 2: confirmatory factor analyses, Phase 3: reliability analysis, and Phase 4: subgroup validity analysis. The results from the adaptation process revealed that the underlying structure of the CTAS is formed by three constructs that measure students' thoughts, off-task behaviors, and autonomic reactions. Internal consistency estimates (coefficient alpha) of scores for the thoughts, off-task behaviors, and autonomic reactions were $.82, .72$, and .75 , respectively. For the total instrument, the reliability coefficient was .88 . All these estimates indicated satisfactory reliability $(>.60)$ for both the whole instrument and its sub-dimensions (Tabachnick and Fidell, 2007). In brief, this implied that the scores on the CTAS are valid and reliable to provide consistent information about students' test anxiety.

\section{Procedure}

The CTAS was administered to students during 2014/2015 academic year. Students were allowed to complete the 30 item instrument within one class period (40 min) in regular school hours. Along with the copy of the instrument, students were also given demographic questions (i.e., school, class affiliation, and gender), written instructions (i.e., requesting students to respond in terms of how they think, feel, or act during a test), and a sample item for practice (i.e., each question is responded with a stem "While I am taking a test..."). Some teachers, who were willing to provide assistance for the researchers, were also present at the class during data collection. While administering the CTAS, the researcher read the written instruction and directions, and then the items one by one to the class. During the administration she walked around the class and checked the desks to avoid time consumption (e.g., students spend too much time on each item) and made sure that each student answered all items in the approximate time required to complete the questionnaire. School administrators, teachers, and students were informed about the scope of the study prior to administration and were assured of confidentiality.

\section{Analyzing of Data}

To examine the first research question the intercorrelations among the overall test anxiety (i.e., total test anxiety) and the sub-dimensions (i.e., total thoughts, total off-task behaviors, and total autonomic reactions) of the CTAS were analyzed by the Pearson's correlation coefficient analysis. The Pearson correlation coefficients were interpreted as small ( $>.10)$, medium (>.30), and high ( $>.50)$ according to Cohen's criteria. To examine the second research question, a One-Way analysis of variance (ANOVA) was performed with one dependent variable (total test anxiety) and one independent variable with two categories (gender: female and male). To examine the third research question, a multivariate approach to analysis of variance (One-Way MANOVA) was performed with one within-subject factor (3 sub-dimensions) and one between-subject factor (gender). Three dependent variables were used: thoughts, off-task behaviors, and autonomic reactions. The independent variable was gender.

Accordingly, gender was coded as $1=$ Female and $2=$ Male and total scores for each sub-dimension (i.e., thoughts, offtask behaviors, and autonomic reactions) and the whole test (i.e., test anxiety). Following that coding process, preliminary assumption testing was conducted including univariate normality and homogeneity of variance matrices and no violations were detected (i.e., Levene's test, $p>.05$ ). For univariate results, the $F$ test criterion was applied using the significance level .05. For multivariate results, the Wilks' Lambda criterion was applied using the significance level .05. Eta squared $\left(\eta^{2}\right)$ was separately calculated to present the effect size. The $\eta^{2}$ was classified as small (.01), medium (.06) and large (.14) regarding Cohen's (1988) criteria. PASW Statistics 18 (Statistical Package for the Social Sciences Inc., 2010) was used to conduct all the statistical analyses.

\section{Results}

\section{Descriptive Statistics}

The means and standard deviations of three sub-dimension scores and total test anxiety scores were presented by gender in Table 1. 
Table 1. Descriptive Statistics of Scores on CTAS and Its Sub-dimensions by Gender

\begin{tabular}{|c|c|c|c|c|c|c|c|c|}
\hline & \multicolumn{2}{|c|}{ Thoughts } & \multicolumn{2}{|c|}{$\begin{array}{c}\text { Off-Task } \\
\text { Behaviors }\end{array}$} & \multicolumn{2}{|c|}{$\begin{array}{c}\text { Autonomic } \\
\text { Reactions }\end{array}$} & \multicolumn{2}{|c|}{ Test Anxiety } \\
\hline & $M$ & $S D$ & $M$ & $S D$ & $M$ & $S D$ & $M$ & $S D$ \\
\hline Female & 33.66 & 8.58 & 15.18 & 4.58 & 19.32 & 5.43 & 68.16 & 15.41 \\
\hline Male & 31.89 & 7.52 & 16.07 & 4.59 & 17.94 & 5.43 & 65.91 & 14.84 \\
\hline Total & 32.77 & 8.10 & 15.63 & 4.60 & 18.62 & 5.47 & 67.02 & 15.15 \\
\hline
\end{tabular}

Note. $N=414$ with Test anxiety; Female $=205$; Male $=209$

For the total test anxiety, the mean score was 67.02 indicating that the majority of students felt nervous and stressed before a test $(M>37$ on a 4-point scale). When the dimensions of test anxiety were inspected separately, thoughts $(M=$ $32.77 ; S D=8.10)$ scores were the highest, followed by autonomic reactions $(M=18.62 ; S D=5.47)$ and off-task behaviors $(M=15.63 ; S D=4.60)$. These scores reflected that students had more psychological (thoughts) concerns than they had physiological (autonomic reactions) and/or behavioral (off-task behaviors) worries about taking tests.

More specifically, the differences between gender groups' means were minor on almost all sub-dimensions of CTAS (see Table 1), but the females reported slightly higher than males on all dimensions, except for off-task behaviors. This indicated that, for instance, females worry more than males about what their parents will say (thoughts) and thus feel scared (autonomic reactions). On the other hand, males were more inattentive than females, and that they look around the classroom and/or other students during a test (off-task behaviors).

\section{Relationships among Overall Test Anxiety and Thoughts, Off-Task Behaviors, and Autonomic Reactions}

The first research question concerned the relationship between the overall test anxiety and its three components, in general as well as the relationships among the three components of test anxiety, in particular. Results from the Pearson correlation coefficient analysis within the whole data $(N=414)$ indicated that there were positive and statistically significant correlations between overall test anxiety and thoughts, off-task reactions, and autonomic reactions $(r$ from .74 to $.83, p=.01)$. The Pearson correlation coefficients can be interpreted as large (>.50) according to Cohen's (1988) criteria. Results also showed that there were positive and statistically significant relationships among thoughts, off-task reactions, and autonomic reactions ( $r$ from .45 to .57, $p=.01$ ). The Pearson correlation coefficients can be interpreted as medium $(>.30)$ to large $(>.50)$ according to Cohen's (1988) criteria. In this regard, the strongest relationship among the three components of test anxiety was between thoughts and autonomic reactions and to a lesser extent, between thoughts and off-task behaviors (see Table 2). It is noteworthy that the significantly high correlations among overall test anxiety, thoughts, off-task reactions, and autonomic reactions signaled multicollinearity among the study constructs. In order to avoid problems in interpreting the study results (e.g. negatively influencing statistical significance tests of the coefficients) as a function of the influence of multicollinearity on the magnitude of regression weights as well as the potential inflation of their standard error, thereby negatively influencing statistical significance tests of these coefficients.

Table 2. The Pearson Correlations among the Study Variables

\begin{tabular}{lcccc}
\hline \multicolumn{1}{c}{ Variables } & 1 & 2 & 3 & 4 \\
\hline 1. Overall Test Anxiety & - & & & \\
2. Thoughts & $.88^{* *}$ & - & & \\
3. Off-task Behaviors & $.74^{* *}$ & $.45^{* *}$ & - & - \\
4. Autonomic Reactions & $.83^{* *}$ & $.57^{* *}$ & $.55^{* *}$ & - \\
\hline
\end{tabular}

Note. ${ }^{* *}$ Correlation is significant at .01 level (two-tailed).

The thoughts, which includes a variety of worry cognitions (e.g., self critiques) that occur during testing, was strongly and positively associated with autonomic reactions. This reflected that students, who feel anxious while taking exams, have high test-related stress and thus show somatic responses such as stomach problems. On the other hand, there was a small correlation between thoughts and off-task behaviors indicating that students, who feel anxious, may tend to exhibit distracted behaviors such as not focusing on the test. In addition, off-task behaviors and autonomic reactions were moderately and positively related to one another. This means that students, who display auto-manipulation (e.g., playing with hair), also have test-related concerns and thus react stressfully (e.g., fast heart beat).

\section{Gender Differences in Overall Test Anxiety}

The second research question was how the test anxiety, in general, differs between female and male students in Grade 4. A one-way ANOVA, with gender as the independent variable, the overall test anxiety as dependent variable, was conducted to explore the effect of gender on children's overall test anxiety, as measured by the CTAS (see Table 3). Results revealed that there was a statistically significant difference between females and males, $F(1,412)=40.79, p=$ $.01, \eta^{2}=.099$. An inspection of the $\eta^{2}$ indicated a medium effect (Cohen, 1988), and that the gender explained $9.9 \%$ of the differences in the overall test anxiety of fourth grade students. 
Table 3. Summary Statistics for the One-Way ANOVA

\begin{tabular}{lcccc}
\hline \multicolumn{1}{c}{ Total Test Anxiety } & Sum of Squares & $d f$ & $p$ & $\eta^{2}$ \\
\hline Between Groups & 479.697 & 1 & $.01^{*}$ & .099 \\
Within Groups & 4845.424 & 412 & & \\
Total & 5325.121 & & & \\
\hline
\end{tabular}

${ }^{*} p<.05$

\section{Gender Differences in Thoughts, Off-Task Behaviors and Autonomic Reactions}

The third research question was how the three sub-dimensions, in particular, differ between female and male students in Grade 4. Summary statistics for the one-way MANOVA performed on the CTAS, with gender as between subjects factor, the three sub-dimensions as within subjects factor was displayed in Table 4.

Table 4. Summary Statistics for the One-Way MANOVA

\begin{tabular}{lccc}
\hline \multicolumn{1}{c}{ Sub-dimensions } & $F(1,412)$ & $p$ & $\eta^{2}$ \\
\hline Thoughts & 4.88 & $.02^{*}$ & .010 \\
Off-Task Behaviors & 3.87 & $.03^{*}$ & .011 \\
Autonomic Reactions & 9.42 & $.01^{*}$ & .014 \\
\hline
\end{tabular}

When the results for the sub-dimensions were considered separately, there were statistically significant differences across the gender variable for the thoughts, $F(1,412)=4.88, p=.02, \eta^{2}=.010$; off-task behaviors, $F(1,412)=3.87, p=$ $.03, \eta^{2}=.007$, and autonomic reactions, $F(1,412)=9.42, p=.01, \eta^{2}=.014$. Across each of the sub-dimensions except off-task behaviors, the females' mean scores were higher than that of the males (see Table 1) with this trend most evident across the thoughts and to a lesser extent, autonomic reactions. Furthermore, an effect size index $\eta^{2}$ was calculated separately. The $\eta^{2}$ values of $.010, .011$, and .014 could be interpreted as quite a small effect (Cohen, 1988) indicating that $1 \%, 1.1 \%$, and $1.4 \%$ of the variance in thoughts, off-task behaviors, and autonomic reactions, respectively can be explained by gender.

\section{Discussion and Conclusion}

The primary aim of the present study was to analyze the gender differences in fourth grade students' thoughts, off-task behaviors, and autonomic reactions. Replicating the results of recent international (Bandalos et al., 1995; Lowe and Lee, 2008; Putwain, 2007; Segool et al., 2010) and national (e.g., Bacanli and Surucu, 2006; Oksan et al., 2013) studies, the findings pointed to the significant gender differences in overall test anxiety as well as in its three components favoring females.

With respect to differences by dimensions, several works illustrated that thoughts and autonomic reactions show the most relevant differences in favor of females (e.g., Wren and Benson, 2004) and that no significant differences are evident in off-task behaviors (e.g., Nyroos et al., 2015). Unlike these findings, in the current analysis of Turkish data, significant gender differences were found by thoughts and autonomic reactions in favor of females, and also considering the off-task behaviors in favor of males. In contrast with researchers contending that there were no significant gender differences in none of the three dimensions of test anxiety (see e.g., Putwain and Daniels, 2010), in this analysis, significant gender differences were found across thoughts, off-task behaviors, and autonomic reactions. Moreover, this pattern was more prominent in the autonomic reactions dimension than in the thoughts and off-task behaviors dimensions. It seems likely and logical that while taking a test females and males may become anxious for different reasons or be anxious about different things with particular reference to psychological, behavioral, and/or physiological aspects of test anxiety. It is noteworthy that females and males experience different levels of test anxiety and that gender differences may not expose true differences in the level of test anxiety, but gender differences may reflect the degree to which females and males are willing to admit their test anxiety (Bodas and 0llendick, 2005) for three reasons. First, females' sensitivity in social approval from adults may reflect their being more test anxious than males (Maehr and Nicholls, 1980). Second, males' sensitivity in peer evaluation may lead them to come under more pressure to attract their counterparts (Wigfield and Eccles, 1990). Finally, females may find assessment situations as more threatening (Putwain, 2008).

All findings of this work lead to the conclusion that, in the fourth grade, a gender gap in the test anxiety - specifically in thoughts, off-task behaviors, and autonomic reactions - exists. These results are particularly important in relation to the fact that different methods and perspectives were used to evaluate gender differences in test anxiety across the three dimensions and that these analyses have been done for the first time on Turkish national data.

A correlation analysis also confirmed researchers' hypotheses regarding a positive association among thoughts, off-task behaviors, and autonomic reactions. Consistent with previous results (Putwain and Daniels, 2010; Wren and Benson, 2004), the relationships among the dimensions revealed the thoughts was highly related to autonomic reactions (.57) and less so with the off-task behaviors (.45), whereas the relationship between the autonomic reactions and off-task 
behaviors was moderate (.55). One could then presume that students who worry about failing (thoughts) are more likely to feel nervous (autonomic reactions) than they are to look around the classroom (off-task behaviors) while they are taking a test.

\section{Contribution of the Present Study to Test Anxiety Research}

The findings supplement the existing research in several respects. First, the present study was based on a large, nationally representative sample of 414 fourth grade students from 15 classes. Second, students' test anxiety was assessed by the CTAS, which was originally developed by Wren and Benson (2004). The CTAS was used in prior crosscultural research (see Putwain and Daniels, 2010); however, the present study is the first to address the gender differences in test anxiety in general, and its three dimensions in particular, with fourth grade students by using its adapted version (see Aydin and Bulgan, 2017). Third, the present study examined the gender differences in all the three dimensions of test anxiety (i.e., thoughts, off-task behaviors, and autonomic reactions). Most previous studies have focused on the differences in the worry and emotionality dimensions of test anxiety (e.g., Cassady and Johnson, 2002; Everson et al., 1991) and/or solely investigated these differences in the overall test anxiety (e.g., Putwain, 2007).

However, in accordance with the literature review (e.g., Hembree, 1988; Seipp and Heinrich, 1991) that generally highlighted the links between worry and emotionality dimensions of test anxiety, the results were able to confirm the importance of thoughts, off-task behaviors, and autonomic reactions with regard to the diverse effects of socialization and scholastic ability on different genders.

\section{Educational Implications}

Obviously, there is increasingly evaluative practices that students encounter as they move through school years. Then, what are the implications of the findings for test anxiety research? The present study provides strong evidence that females report higher levels of overall test anxiety than males. Teachers may, thus, be able to improve their awareness of this situation by taking into consideration the fact that gender differences in test anxiety are not merely due to females' experiencing higher levels of emotionality, and it may well be worth focusing more on the levels of academic ability.

The picture that emerges for the three dimensions of test anxiety is similar. Results point to the females' higher test anxiety within thoughts, off-task behaviors, and autonomic reactions. In my view, the similarity among the results reflects the difficulties females face in an evaluative setting: The perceptions of threat by females that arise from their heightened self-doubt regarding the ability to cope with an exam.

Given these results, how should instruction be designed to reduce test anxiety with particular attention to females? Several researchers (Yeo, Goh, and Liem, 2016; von Der Embse, 2013) suggested school-based programs in which school partnerships were built to conduct prevention and intervention programs with a particular focus on test anxiety. Likewise, Ergene (2003) suggested that test anxiety intervention programs should be designed for elementary, middle, and secondary school students. These suggestions are relevant to the gender differences found in the present study, challenging that well-structured interventions to reduce females' test anxiety.

But how should teachers or researchers go about designing interventions that both avoid test anxiety and improve test performance of students in general and females in particular? One possibility may be to use cognitive-behavioral methods (Sapp, 1993; Sapp and Farrell, 1994) or implement skill-building interventions (Gregor, 2005) to reduce test anxiety and thus increase the performance in tests. For instance, teachers may encourage females to overlearn material covered in class and that the learning material to the point of mastery can result in females' experiencing less worry about doing something wrong (thoughts) and energize fewer nervous actions (off-task behaviors), and thus feel less scared (autonomic reactions). Teachers can also use problem-solving techniques and social support to reduce test anxiety with females. For instance, the more test anxious females can gain a sense of social support if they prepare for test with a supportive girl or a boyfriend. If a stronger female/male is paired with a weaker female during a classroom activity the stronger student not only serves as a model for effective problem-solving or study habits but also serves as a form of social support in the context of peer tutoring. A further possibility would be to pose a series of questions to encourage females to find effective ways for overcoming evaluative situations. Teachers can provide supportive counseling to test anxious females by asking, for instance, (i) When do you feel most anxious about taking tests?, (ii) Tell me what exactly do you feel during a test?, and (iii) Can you tell me some techniques that you applied in terms of reducing your test anxiety? Such questions have the potential of a decline in the level of test anxiety, depending on the approach chosen.

\section{Limitations and Future Research}

There are several limitations within the present study. First, student reports were the sole source of information. Empirical studies assessing characteristics of the test anxiety may draw on a combination of data sources such as external observers and teacher reports or both. Each perspective can be assumed to assess at least slightly different dimensions of the test anxiety in question. A combination of methods (e.g., classroom observations followed by individual interviews) might provide deeper insights into the gender differences in future research. Second, the present study was not able to address the causality. Results implied that there is gender disparity in test anxiety. The only way 
of addressing causality would be a carefully designed intervention study (i.e., test anxiety reduction program) in which students were assigned to different treatments. To date, many studies have systematically evaluated test anxiety intervention programs (see Ergene, 2003 for a review). Intervention studies could complement the present research, providing valuable insights into the mechanisms of test anxiety in relation to thoughts, off-task behaviors, and autonomic reactions and its differential influences on females and males.

Third, the generalizability of the present results remains uncertain. Findings apply specifically to fourth graders and to students from a different culture. Previous research has identified differences in test anxiety across grades (Wren and Benson, 2004) and cultures (Bodas and Ollendick, 2005). Future studies should therefore analyze test anxiety differences across grade levels (e.g., elementary and secondary) and cultures (e.g., United Kingdom and United States). In order to test the generalizability of the differences found in the current study, cross-cultural studies are also necessary.

To conclude, the present research added to prior research by demonstrating the importance of not only the overall test anxiety but also its three dimensions: thoughts, off-task behaviors, and autonomic reactions for different genders. Moreover, it confirmed the relationships among these dimensions as a further indicator of the characteristics of females and males with different levels of test anxiety in thoughts, off-task behaviors, and autonomic reactions. In sum, the findings extend the psychological, behavioral, and physiological understanding of the circumstances under which students exhibit distracted manifestations in test completion and of how that scientific understanding can enhance gender differences in the overall test anxiety.

\section{Acknowledgements}

The author is very grateful to all the students, teachers and head teachers who participated in the present study. The author would like to acknowledge the contributions of Professor Douglas G. Wren, Department of Research, Evaluation and Assessment, Virginia, USA, for his kind assistance in providing access to the Children's Test Anxiety Scale. The author extends her thanks to the two anonymous reviewers who provided feedback on the original version of this paper.

\section{References}

Abu-Rabia, S. (2004). Teachers' role, learners' gender differences, and FL anxiety among seventh grade students studying English as a FL. Educational Psychology, 24(5), 711-721. doi: 10.1080/0144341042000263006

AERA, APA, \& NCME. (1999). Standards for educational and psychological testing. Washington DC: Author.

Andre, T., Whigham,M., Hendrickson, A., \& Chambers, S. (1999). Competency beliefs, positive affect, and gender stereotypes of elementary students and their parents about science versus other school subjects. Journal of Research in Science Teaching, 36(6), 719-747. doi: /10.1002/(SICI)1098-2736(199908)36:6<719::AIDTEA8>3.0.CO;2-R

Aydin, U., \& Bulgan, G. (2017). Cocuklarda Sinav Kaygisi Olcegi'nin Turkce uyarlamasi [Adaptation of Children's Test Anxiety Scale to Turkish]. Ilkogretim Online [Elementary Education Online], 16(2), 887-899. doi:10.17051/ilkonline.2017.304742

Bacanli, F., \& Surucu, M. (2006). Ilkogretim 8. sinif ogrencilerinin sinav kaygilari ve karar verme stilleri arasindaki iliskilerin incelenmesi [An examination of the relationship between test anxiety and decision making styles of elementary school 8th grades students]. Kuram ve Uygulamada Egitim Yonetimi [Educational Administration: Theory and Practice], 45, 7-35.

Bodas, J., \& Ollendick, T. H. (2005). Test anxiety: A cross-cultural perspective. Clinical Child and Family Psychology Review, 8(1), 65-88. doi: 10.1007/s10567-005-2342-x

Bodas, J., Ollendick, T. H., \& Sovani, A. V. (2008). Test anxiety in Indian children: A cross-cultural perspective. Anxiety, Stress, \& Coping, 21(4), 387-404. doi: 10.1080/10615800701849902

Cassady, J. C., \& Johnson, R. E. (2002). Cognitive test anxiety and academic performance. Contemporary Educational Psychology, 27(2), 270-295. doi:10.1006/ceps.2001.1094

Cohen, J. (1988). Statistical power analysis for the behavioral sciences. Hillsdale, NJ: Lawrence Earlbaum Associates.

Cohen, J., Cohen, P., West, S. G., \& Aiken, L. S. (2003). Applied multiple regression/correlation analysis for the behavioral sciences. Mahwah, NJ: Erlbaum.

Ergene, T. (2003). Effective interventions on test anxiety reduction. School Psychology International, 24(3), 313 - 328. doi: $10.1177 / 01430343030243004$

Everson, H. T., Millsap, R. E., \& Rodriguez, C. M. (1991). Isolating gender differences in test anxiety: A confirmatory factor analysis of the Test Anxiety Inventory. Educational and Psychological Measurement, 51(1), 243-251. doi: $10.1177 / 0013164491511024$ 
Fischer, W. F. (1970). Theories of anxiety. New York: Harper \&Row.

Gregor, A. (2005). Examination anxiety: Live with it, control it or make it work for you? School Psychology International, 26(5), 617 - 635. doi: 10.1177/0143034305060802

Hancock, D. R. (2001). Effects of test anxiety and evaluative threat on students' achievement and motivation. The Journal of Educational Research, 94(5), 284-290. doi: 10.1080/00220670109598764

Hembree, R. (1988). Correlates, causes, and treatment of test anxiety. Review of Educational Research, 58(1), 47-77. doi: 10.3102/00346543058001047

Hill, K. T., \& Wigfield, A. (1984). Test anxiety: A major educational problem and what can be done about it. The Elementary School Journal, 85(1), 105-126. doi: 10.1086/461395

Hong, E. (1999). Test anxiety, perceived test difficulty, and test performance: Temporal patterns of their effects. Learning and Individual Differences, 11(4), 431-47. doi: 10.1016/S1041-6080(99)80012-0

Jacklin, C. N. (1989). Female and male: Issues of gender. American Psychologist, 44(2), 127.

Liebert, R. M., \& Morris, L. W. (1967). Cognitive and emotional dimensions of test anxiety: A distinction and some initial data. Psychological Reports, 20(3), 975-978. doi: 10.2466/pr0.1967.20.3.975

Little, R. J. (1988). A test of missing completely at random for multivariate data with missing values. Journal of the American Statistical Association, 83(404), 1198-1202. doi: 10.1080/01621459.1988.10478722

Lowe, P. A., \& Lee, S.W. (2008). Factor structure of the Test Anxiety Inventory for Children and Adolescents (TAICA): Scores across gender among students in elementary and secondary school settings. Journal of Psychoeducational Assessment, 26(3), 231 - 246. doi: 10.1177/0734282907303773

Ma, X. (1999). A meta-analysis of the relationship between anxiety toward mathematics and achievement in mathematics. Journal for Research in Mathematics Education, 30(5), 520-540. doi: 10.2307/749772

Meijer, J. (2001). Learning potential and anxious tendency: Test anxiety as a bias factor in educational testing. Anxiety, Stress, \& Coping, 14(4), 337-362. doi: 10.1080/10615800108248361

Mulvenon, S. W., Stegman, C. E., \& Ritter, G. (2005). Test anxiety: A multifaceted study on the perceptions of teachers, principals, counselors, students, and parents. International Journal of Testing, 5(1), 37-61. doi: 10.1207/s15327574ijt0501_4

McDonald, A. S. (2001). The prevalence and effects of test anxiety in school children. Educational Psychology, 21(1), 89101. doi: $10.1080 / 01443410020019867$

Nyroos, M., Korhonen, J., Peng, A., Linnanmäki, K., Svens-Liavåg, C., Bagger, A., \& Sjoberg, G. (2015). Cultural and Gender Differences in Experiences and Expression of Test Anxiety Among Chinese, Finnish, and Swedish Grade 3 Pupils. International Journal of School \& Educational Psychology, 3(1), 37-48. doi: 10.1080/21683603.2014.915773

Oksal, A., Durmaz, B., \& Akin, A. (2013). SBS'ye hazirlanan ogrencilerin sinav ve matematik kaygilarinin bazi degiskenler acisindan incelenmesi [An investigation into exam and maths anxiety of students preparing for SBS]. Cumhuriyet International Journal of Education, 2(4), 47-62.

Pintrich, P. R., \& Schrauben, B. (1992). Students' motivational beliefs and their cognitive engagement in classroom academic tasks. In D. Schunk \& J. Meece (Eds.), Student perceptions in the classroom: Causes and consequences (pp. 149-183). Hillsdale, NJ: Erlbaum.

Pintrich, P. R., \& Schunk, D. (1996). Motivation in education: Theory, research, and applications. Upper Saddle River, NJ: Prentice-Hall.

Putwain, D. W. (2007). Test anxiety in UK schoolchildren: Prevalence and demographic patterns. British Journal of Educational Psychology, 77(3), 579-593. doi: 10.1348/000709906X161704

Putwain, D. W. (2008). Deconstructing test anxiety. Emotional and Behavioral Difficulties, 13(2), 141-155. doi: $10.1080 / 13632750802027713$

Putwain, D. W., \& Daniels, R. A. (2010). Is the relationship between competence beliefs and test anxiety influenced by goal orientation?. Learning and Individual Differences, 20(1), 8-13. doi: 10.1016/j.lindif.2009.10.006

Putwain, D. W., Daly, A. L., Chamberlain, S., \& Sadreddini, S. (2016). 'Sink or swim': buoyancy and coping in the cognitive test anxiety-academic performance relationship. Educational Psychology, 36(10), 1807-1825. doi: $10.1080 / 01443410.2015 .1066493$ 
Ringeisen, T., Raufelder, D., Schnell, K., \& Rohrmann, S. (2016). Validating the proposed structure of the relationships among test anxiety and its predictors based on control-value theory: evidence for gender-specific patterns. Educational Psychology, 36(10). doi: 10.1080/01443410.2015.1072134

Sapp, M. (1993). Test anxiety: Applied research, assessment and treatment interventions. Lanham, MD: University Press of America.

Sapp, M., \& Farrell,W. (1994). Cognitive-behavioral interventions: Applications for academically at-risk and special education students. Preventing School Failure, 38(2), 19 - 24. doi:10.1080/1045988X.1994.9944299

Sarason, S. B., Davidson, K. S., Lighthall, F. F., Waite, R. R., \& Ruebush, B. K. (1960). Anxiety in elementary school children. New York: Wiley.

Sarason, I. G. (1980). Test anxiety: Theory, research, and applications. Hillsdale, NJ: Erlbaum.

Schwarzer, R., \& Jerusalem, M. (1992). Advances in anxiety theory: A cognitive process approach. In K. A. Hagtvet \& T. B. Johnsen (Eds.), Advances in test anxiety research (Vol. 7, pp. 2-31). Lisse, The Netherlands: Swets \& Zeitlinger.

Scott, S., \& Haydon, D. (2005). Bernado's statement of ethical research practice with children. Available online at: http://barnados.org.uk (accessed 24th November 2014).

Seipp, B., \& Schwarzer, C. (1996). Cross-cultural anxiety research: A review. In C. Schwarzer, \& M. Zeidner (Eds.), Stress, anxiety, and coping in academic settings (pp. 13-68). Tubingen, Germany: Francke-Verlag.

Spielberger, C. D., Gonzalez, H. P., Taylor, C. J., Algaze, B., \& Anton, W. D. (1978). Examination stress and test anxiety. In C. D. Spielberger \& I. G. Sarason (Eds.), Stress and anxiety (Vol. 5, pp. 167-191). New York: Wiley.

Spielberger, C.D. (1966). Theory and research on anxiety. In C.D. Spielberger (Ed.) Anxiety and behavior (VoI. 1). New York: Academic Press.

Statistical Package for the Social Sciences Inc (2010). PASW statistics 18. Chicago: SPSS Inc.

Tabachnick, B. G. \& Fidell, L. S. (2007). Using multivariate statistics. Boston: Pearson Education.

Udo, M. K., Ramsey, G. P., \& Mallow, J. V. (2004). Science anxiety and gender in students taking general education science courses. Journal of Science Education and Technology, 13(4), 435-446. doi: 10.1007/s10956-004-1465-z

von der Embse, N., Barterian, J., \& Segool, N. (2013). Test anxiety interventions for children and adolescents: A systematic review of treatment studies from 2000-2010. Psychology in the Schools, 50(1), 57-71. doi: $10.1002 /$ pits. 21660

Weems, C. F., Scott, B. G., Taylor, L. K., Cannon, M. F., Romano, D. M., Perry, A. M., \& Triplett, V. (2010). Test anxiety prevention and intervention programs in schools: Program development and rationale. School Mental Health, 2(2), 62-71. doi: 10.1007/s12310-010-9032-7

Wigfield, A., \& Eccles, J. S. (1989). Test anxiety in elementary and secondary school students. Educational Psychologist, 24(2), 159-183. doi: 10.1207/s15326985ep2402_3

Wren, D. G. \& Benson, J. (2004). Measuring test anxiety in children: Scale development and internal construct validation. Anxiety, Stress \& Coping, 17(3), 227-240. doi: 10.1080/10615800412331292606

Yan, J. X., \& Horwitz, E. K. (2008). Learners' perceptions of how anxiety interacts with personal and instructional factors to influence their achievement in English: A qualitative analysis of EFL learners in China. Language Learning, 58(1), 151-183. doi: 10.1111/j.1467-9922.2007.00437.x

Yenilmez, K., \& Ozbey, N. (2006). Ozel okul ve devlet okulu ogrencilerinin matematik kaygi duzeyleri uzerine bir arastirma [A research on mathematics anxiety levels of the students of private school and the other schools]. Uludag Universitesi Egitim Fakultesi Dergisi [Journal of Uludag University Faculty of Education], 19(2), 431-448.

Yeo, L. S., Goh, V. G., \& Liem, G. A. D. (2016). School-based intervention for test anxiety. Child \& Youth Care Forum, 45(1), 1-17. doi: 10.1007/s10566-015-9314-1

Zaslavsky, C. (1994). Fear of math: How to get over it and get on with your life. New Brunswick, NJ: Rutgers University Press.

Zatz, S., \& Chassin, L. (1985). Cognitions of test-anxious children under naturalistic test-taking conditions. Journal of Consulting and Clinical Psychology, 53(3), 393-401. doi: 10.1037/0022-006X.53.3.393

Zeidner, M. (1998). Test anxiety: The state of the art. New York: Plenum.

Zeidner, M., \& G. Mathews. (2005). Evaluation anxiety. In ed. A.J. Elliot and C.S. Dweck (Eds.), Handbook of competence and motivation, 141-163. London: Guildford Press. 